\title{
Organocatalytic controlled anionic ring-opening polymerization of carbazole-containing thiiranes
}

\author{
Aliaksei A. Vaitusionak ${ }^{\mathrm{a}}$, Irina V. Vasilenko ${ }^{\mathrm{a}, *}$, Egle Jatautiene ${ }^{\mathrm{b}}$, Jurate Simokaitiene ${ }^{\mathrm{b}}$, \\ Ausra Tomkeviciene $^{\mathrm{b}}$, Jolita Ostrauskaite ${ }^{\mathrm{b}}$, Juozas V. Grazulevicius ${ }^{\mathrm{b}}$, Sergei V. Kostjuk ${ }^{\mathrm{a}, \mathrm{c}, \mathrm{d}, *}$ \\ ${ }^{a}$ Research Institute for Physical Chemical Problems of the Belarusian State University, 14 Leningradskaya St, 220006 Minsk, Belarus \\ ${ }^{\mathrm{b}}$ Department of Polymer Chemistry and Technology, Kaunas University of Technology, Radvilenu Rd. 19, LT-50254 Kaunas, Lithuania \\ ${ }^{\mathrm{c}}$ Sechenov First Moscow State Medical University, Institute for Regenerative Medicine, 8/2 Trubetskaya St., 119991 Moscow, Russia \\ ${ }^{\mathrm{d}}$ Department of Chemistry, Belarusian State University, 14 Leningradskaya St., 220006 Minsk, Belarus
}

\section{A R T I C L E I N F O}

\section{Keywords:}

Anionic ring-opening polymerization

Controlled polymerization

Organic catalysis

Carbazole-containing monomers and polymers

Charge-transporting materials

\begin{abstract}
A B S T R A C T
The anionic ring-opening polymerization of carbazole-containing monomers, (9-carbazolylmethyl)thiirane (M1) and (3,6-di-tert-butyl-9-carbazolylmethyl)thiirane (M2), with hexanethiol or pentaerythritol tetrakis(3-mercaptopropionate) (PETMP) as initiators and 1,5,7-triazabicyclo[4.4.0]dec-5-ene (TBD) as catalyst at $20^{\circ} \mathrm{C}$ in tetrahydrofuran or N,N-dimethylformamide as solvents has been studied. The polymerization of these monomers proceeds in a living fashion affording linear and star-shaped polymers with controlled molecular weight $\left(M_{n}=4000-15,000 \mathrm{~g} \mathrm{~mol}^{-1}\right)$ and relatively low polydispersity $(\bigoplus<1.3)$. It was demonstrated that end-capping of polymers by trifluoroacetic anhydride allowed to protect thiol end groups from oxidative coupling, which typically leads to the broadening of molecular weight distribution of the synthesized polymers. The thermal, photophysical and electrochemical properties of the synthesized linear and star-shaped polymers were estimated.
\end{abstract}

\section{Introduction}

Poly(N-vinylcarbazole) is one of the extensively studied photoconductive polymers due to its application as hole transporting host in polymer light emitting diodes [1-4]. In order to tune electrochemical and photophysical properties of poly(N-vinylcarbazole), a great variety of polymers containing carbazole moieties in the side chain were successfully synthesized [5-7]. Firstly, poly(meth)acrylates and polystyrenes with pendant carbozolyl group were mainly synthesized through conventional radical mechanism [8-12], although there are several reports where such kind of polymers have been successfully obtained by anionic $[13,14]$ and cationic $[15]$ mechanisms. However, it was difficult to control the molecular weight and architecture of the synthesized polymers that significantly complicated the finding of the correlation between polymer structure and its electronic and photonic properties. The use of controlled radical polymerization technique allowed to prepare well-defined homopolymers [16-18], end-functionalized polymers as well as block copolymers [19-21] and even star polymers [22]. However, these examples are still limited to the polymerization of carbazole-containing (meth)acrylates and styrenes
[23-27].

In this respect, the controlled polymerization of heterocyclic carbazole-containing monomers, which will result in polymers with heteroatom in a main chain, might represent considerable interest and enrich the range of application of carbazole-based polymers [7]. Surprisingly, there are only few examples of ring-opening cationic $[2,28,29]$ or anionic [29-32] polymerization of carbazole-containing oxiranes $[2,28,30,31]$ and thiiranes $[2,29,32]$. In all cases, however, polymerizations proceeded in non-controlled fashion affording low molecular weight polymers $\left(\mathrm{M}_{\mathrm{n}}<3000 \mathrm{~g} \mathrm{~mol}^{-1}\right)$ with high polydispersity ( $(=4-8)$. For example, Andruleviciute et al. [29] showed that cationic photopolymerization of (9-carbazolylmethyl)thiirane (M1) is accompanied by many side reactions to afford polymers with $\mathrm{M}_{\mathrm{n}}=3100 \mathrm{~g} \mathrm{~mol}^{-1}$ and $Ð=8$.8. The $\mathrm{BF}_{3} \mathrm{OEt}_{2}$-coinitiated cationic polymerization of this monomer leads to polymers with $\mathrm{M}_{\mathrm{n}}=2860 \mathrm{~g} \mathrm{~mol}^{-1}$ and $\mathrm{Ð}=4.5$ [2], while anionic polymerization in the presence of BuLi as initiator results in poly-(9-(thiiran-2-ylmethyl)9H-carbazole) with slightly higher molecular weight $\left(M_{n}=5800 \mathrm{~g} \mathrm{~mol}^{-1}\right)$ but still high polydispersity $(\boxplus=4.4)$ [29].

On the other hand, anionic ring-opening polymerization of the

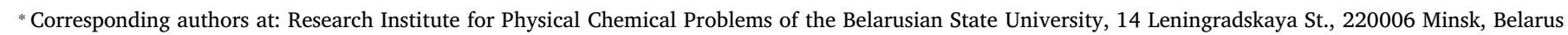
(S.V. Kostjuk, I.V. Vasilenko).

E-mail addresses: vasilenkoi@bsu.by (I.V. Vasilenko), kostjuks@bsu.by (S.V. Kostjuk). 


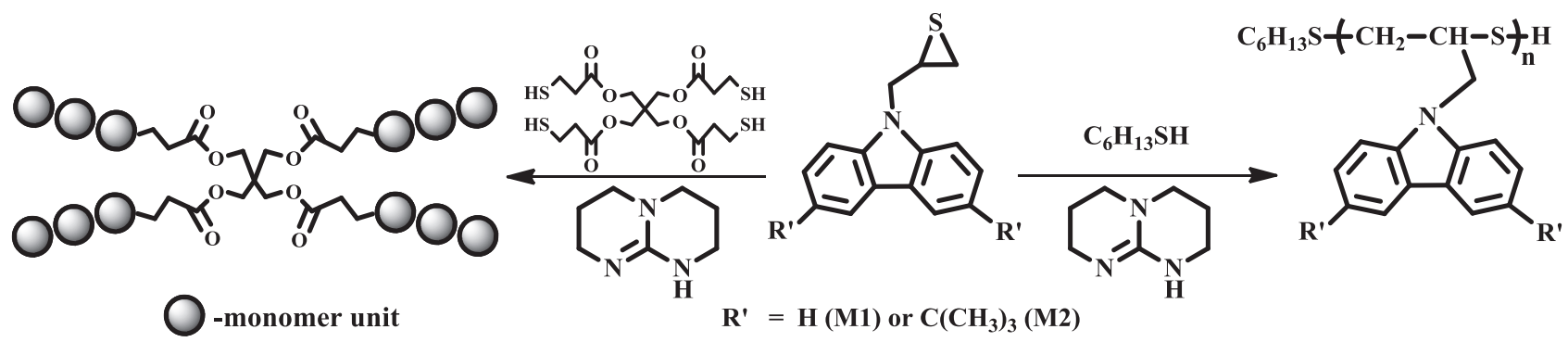

Scheme 1. Anionic ring-opening polymerization of M1 and M2 with $\mathrm{C}_{6} \mathrm{H}_{13} \mathrm{SH} / \mathrm{TBD}$ and PETMP/TBD initiating systems.

simplest thiiranes, such as methylthiirane or 2-hydroxymethylthiirane, can proceed in a living fashion in the presence of nucleophilic or basic initiators under high purity and aprotic conditions [33-36]. However, the deactivation of growing species occurs rapidly at the end of the polymerization [37]. Nevertheless, the living anionic ring-opening polymerization of methylthiirane in the presence of initiating system based on thiols as initiators and 1,8-diazabicyclo[5.4.0]undec-7-ene (DBU) as catalyst has been reported by Nicol et al. in 1999 [37]. In this system, DBU was used in strictly stoichiometric amount to initiator providing fast exchange between thiol and thiolate form that allows to synthesize polymethylthiirane with controlled molecular weight $\left(\mathrm{M}_{\mathrm{n}}=1200-54,300 \mathrm{~g} \mathrm{~mol}^{-1}\right)$ and quite low polydispersity $(\bigoplus<1.1)$. The same team also reported the synthesis of star-shaped polymethylthiiranes using 1,2,3-propanetrithiol and pentaerythritol tetrakis (3-mercaptopropionate) (PETMP) as multifunctional initiators in conjunction with DBU as catalyst [38].

In this article, we report on living anionic ring-opening polymerization of two thiirane derivatives containing carbazole group, (9carbazolylmethyl)thiirane (M1) and (3,6-di-tert-butyl-9-carbazolylmethyl)thiirane (M2) (Scheme 1) using 1,5,7-triazabicyclo[4.4.0] dec-5-en (TBD) as catalyst in conjunction with hexanethiol and pentaerythritol tetrakis(3-mercaptopropionate) (PETMP) as initiators. The linear and star-shaped polymers with controlled molecular weight and low polydispersity were synthesized for the first time from these two carbazole-containing monomers. We also demonstrated here that endcapping of the synthesized polymers by trifluoroacetic anhydride allows to prevent oxidative coupling of the thiolate end groups. A great advantage of proposed approach for the preparation of host polymers for polymer light emitting devices is the use of metal-free organic catalyst for conducting the polymerization that excludes the expensive stage of polymer purification from metal impurities.

\section{Results and discussion}

\subsection{DFT calculations}

In order to estimate the reactivity of (9-carbazolylmethyl)thiirane (M1) and (3,6-di-tert-butyl-9-carbazolylmethyl)thiirane (M2) in the anionic ring-opening polymerization, density functional theory (DFT) B3LYP method was used to calculate the charges on the C1 carbon atom of thiirane ring of methylthiirane, M1 and M2, respectively. The negative charge on carbon atom of methylene group for both M1 $(-0.441)$ and M2 $(-0.441)$ monomers is almost the same as that for methylthiirane $(-0.448)$ (Table 1$)$. Based on these calculations, it was concluded that M1 and M2 can be polymerized in the presence of the

Table 1

NBO atomic charges for methylthiirane, M1 and M2.

\begin{tabular}{ll}
\hline Monomer & Charge on C1 \\
\hline Methylthiirane & -0.448 \\
M1 & -0.441 \\
M2 & -0.441
\end{tabular}

initiating system, which consists of thiol and bicyclic strong guanidine base. In this work we used 1,5,7-triazabicyclo[4.4.0]dec-5-ene (TBD), which is characterized by the higher activity in the ring-opening polymerization of cyclic ethers in comparison with DBU [39-42].

\subsection{Synthesis of linear polymers}

In a first series of experiments, the effect of solvent polarity, temperature and initiator to catalyst ratio on the anionic ring-opening polymerization of $\mathbf{M} 1$ with $\mathrm{C}_{6} \mathrm{H}_{13} \mathrm{SH} / \mathrm{TBD}$ initiating system has been investigated (Table 2). The reaction is much faster in more polar DMF ( $\varepsilon=36.7$ ) than in THF $(\varepsilon=7.6)$ (entries 1,2 , Table 2 ) that could be explained by the shift of the equilibrium between thiol and thiolate ion (Scheme 1) toward thiolate ion in a more polar solvent. On the other hand, a good correlation between experimental and theoretical molecular weights and low polydispersity are observed for polymers synthesized in both solvents. The decrease of TBD to thiol ratio leads to some decrease of reaction rate as well as to polymers with higher than theoretical molecular weight and relatively high polydispersity (entries 3,4 , Table 2) due to slow and/or incomplete initiation. The decrease of the reaction temperature leads to strong reduction of the reaction rate as well as to polymers with lower than theoretical molecular weight (entries 2, 5, Table 2). Taking into account these preliminary studies, all further experiments were conducted at $20^{\circ} \mathrm{C}$ and at equimolar initiator to catalyst ratio.

To proof the livingness of the anionic ring-opening polymerization of M1 with $\mathrm{C}_{6} \mathrm{H}_{13} \mathrm{SH} / \mathrm{TBD}$ initiating system, the polymerizations were performed at different monomer to initiator ratios. The increase of monomer to initiator ratio results in the increase of molecular weight of polymers synthesized in THF, although experimental values of $M_{n}$ are lower than theoretical ones (entries 2, 6, Table 2). The underestimation of $\mathrm{M}_{\mathrm{n}}$ values is consistent with the determination of molecular weight by SEC calibrated against polystyrene standards. Indeed, $\mathrm{M}_{\mathrm{n}} s$ determined by NMR are much closer to theoretically calculated molecular weights (Table 2). More accurate control of the molecular weights of the obtained linear poly-(9-carbazolylmethyl)thiiranes is observed in DMF: $M_{n}$ increases with decreasing initiator concentration up to $M_{n}=16,000 \mathrm{~g} \mathrm{~mol}^{-1}$, experimental values of $M_{n}$ correlate well with theoretical ones, while polydispersity is slightly lower in comparison with that for polymers prepared in THF (entries 1, 7, 8, Table 2). Despite of better control over the polymerization of M1 with $\mathrm{C}_{6} \mathrm{H}_{13} \mathrm{SH} /$ TBD initiating system in DMF, the kinetic investigations were performed in THF due to the extremely high reaction rate in DMF as a solvent (Table 2).

As shown in Fig. 1a, the first order-plots are linear and passed through the zero for different $[\mathrm{M}] /[\mathrm{I}]$ ratios studied. The numberaverage molecular weights of the obtained polymers increase in direct proportion to monomer conversion, while experimental values of $M_{n}$ correlate well with theoretical ones for $[\mathrm{M}] /[\mathrm{I}]=20$. At higher $[\mathrm{M}] /[\mathrm{I}]$ ratio $([\mathrm{M}] /[\mathrm{I}]=40)$, some deviation of experimental values of molecular weights from theoretical line is observed (Fig. 1b) due to the underestimation of $M_{n}$ of poly-(9-carbazolylmethyl)thiiranes by SEC calibrated against polystyrene standards. The polydispersity is low and 
Table 2

Controlled anionic ring-opening polymerization of M1 and M2 using $\mathrm{C}_{6} \mathrm{H}_{13} \mathrm{SH} / \mathrm{TBD}$ initiating system. ${ }^{\mathrm{a}}$

\begin{tabular}{|c|c|c|c|c|c|c|c|c|c|}
\hline Entry & Monomer & Solvent & {$[\mathrm{M}] /[\mathrm{I}]$} & Time (min) & Conv (\%) & $\mathrm{M}_{\mathrm{n}}(\mathrm{NMR})^{\mathrm{b}}$ & $\mathrm{M}_{\mathrm{n}}(\text { theor })^{\mathrm{c}}\left(\mathrm{g} \mathrm{mol}^{-1}\right)$ & $\mathrm{M}_{\mathrm{n}}^{\mathrm{d}}\left(\mathrm{g} \mathrm{mol}^{-1}\right)$ & $\bigoplus^{\mathrm{d}}$ \\
\hline 1 & M1 & DMF & 20 & 0.25 & 100 & - & 4900 & 4400 & 1.21 \\
\hline 2 & M1 & THF & 20 & 15 & 100 & 5380 & 4900 & 4700 & 1.25 \\
\hline $3^{e}$ & M1 & THF & 20 & 20 & 91 & - & 4500 & 6100 & 1.35 \\
\hline $4^{f}$ & M1 & THF & 20 & 20 & 92 & - & 4500 & 6100 & 1.33 \\
\hline $5^{g}$ & M1 & THF & 20 & 90 & 66 & 2400 & 3300 & 1400 & 1.18 \\
\hline 6 & M1 & THF & 40 & 60 & 100 & - & 9700 & 7000 & 1.20 \\
\hline 7 & M1 & DMF & 40 & 0.50 & 100 & 8300 & 9700 & 7900 & 1.12 \\
\hline 8 & M1 & DMF & 80 & 1 & 100 & - & 19,250 & 15,700 & 1.18 \\
\hline 9 & M2 & THF & 20 & 60 & 100 & 8200 & 7100 & 5400 & 1.19 \\
\hline
\end{tabular}

a Polymerization conditions: $[\mathrm{M}]=0.3 \mathrm{M}$; $[\mathrm{TBD}] /\left[\mathrm{C}_{6} \mathrm{H}_{13} \mathrm{SH}\right]=1 ; \mathrm{T}=20^{\circ} \mathrm{C}$.

b Calculated from ${ }^{1} \mathrm{H}$ NMR spectra.

c Calculated with equation: $M_{n}$ (theor) $=M_{n}(M) \times\left([M]_{0} /[I]_{0}\right)+M_{n}(I)$.

d Determined by SEC in THF against polystyrene standards.

e $[\mathrm{TBD}] /[\mathrm{C} 6 \mathrm{H} 13 \mathrm{SH}]=0.5$.

f $[\mathrm{TBD}] /[\mathrm{C} 6 \mathrm{H} 13 \mathrm{SH}]=0.25$.

g $\mathrm{T}=-15^{\circ} \mathrm{C}$.

does not change with the increasing of monomer conversion for both of $[\mathrm{M}] /[\mathrm{I}]$ ratios studied (Fig. 1b). Moreover, the SEC traces shift toward high molecular weight region with the increase of monomer conversion (Fig. 1c). These results confirm that anionic ring-opening polymerization of M1 with $\mathrm{C}_{6} \mathrm{H}_{13} \mathrm{SH} / \mathrm{TBD}$ initiating system proceeds in a living fashion.

The anionic ring-opening polymerization of another thiirane monomer, (3,6-di-tert-butyl-9-carbazolylmethyl)thiirane (M2), was then briefly investigated using the same initiating system at $20^{\circ} \mathrm{C}$ and at equimolar initiator to catalyst ratio. As it can be seen from Fig. S1a and S1b, the polymerization of M2 also proceeds in a living fashion: the first-order plot is linear, while $M_{n}$ increases with increasing conversion and polydispersity is low ( $\mathrm{D}<1.2$ ). Interestingly, the rate of the polymerization of M2 is lower than that of M1 (Fig. S1a) despite of similar values of the negative charge on $\mathrm{C} 1$ carbon atom (Table 1 ). The observed difference in the polymerization rate for $\mathbf{M} 1$ and $\mathbf{M} 2$ can be explained by steric hindrance arising during the polymerization of bulky M2.
The chain end structure of the synthesized polymers was analysed by ${ }^{1} \mathrm{H}$ NMR spectroscopy (Fig. 2, Fig. S2). Among the signals of aliphatic (1.5-4.5 ppm) and aromatic $(6.5-8.0 \mathrm{ppm})$ protons of the main chain, the signals of methyl ( $i, 0.8-0.9 \mathrm{ppm})$ and methylene protons $(j$ $(1.25 \mathrm{ppm}), k(\sim 1.55 \mathrm{ppm}), l(\sim 2.80 \mathrm{ppm}))$ of initiator fragment in the polymer chain could be easily identified. The signal of proton of thiol group at the chain end $(h, 2.0-2.1 \mathrm{ppm})$ overlaps with the signals of main chain protons. Taking into account the overlapping of signals of methylene protons $(k, l)$ of initiator fragment with the main chain protons signals, $M_{n}$ (NMR) was calculated based on the intensities of signal of methyl protons of initiator fragment at $0.8-0.9 \mathrm{ppm}(i)$ and methylene protons $(c)$ at $3.9 \mathrm{ppm}$. The number-average molecular weights for poly-(9-carbazolylmethyl)thiirane calculated as $\mathrm{M}_{\mathrm{n}}(\mathrm{NMR})=[3 \mathrm{I}(c) / 2 \mathrm{I}(i)] \times \mathrm{M}_{\mathrm{r}}(\mathrm{M} 1)+\mathrm{M}_{\mathrm{r}}\left(\mathrm{C}_{6} \mathrm{H}_{13} \mathrm{SH}\right)$ were typically slightly higher than those obtained by SEC (Table 2). These data confirm some underestimation of $\mathrm{M}_{\mathrm{n}} \mathrm{s}$ determination by SEC against polystyrene standards for linear polymers.
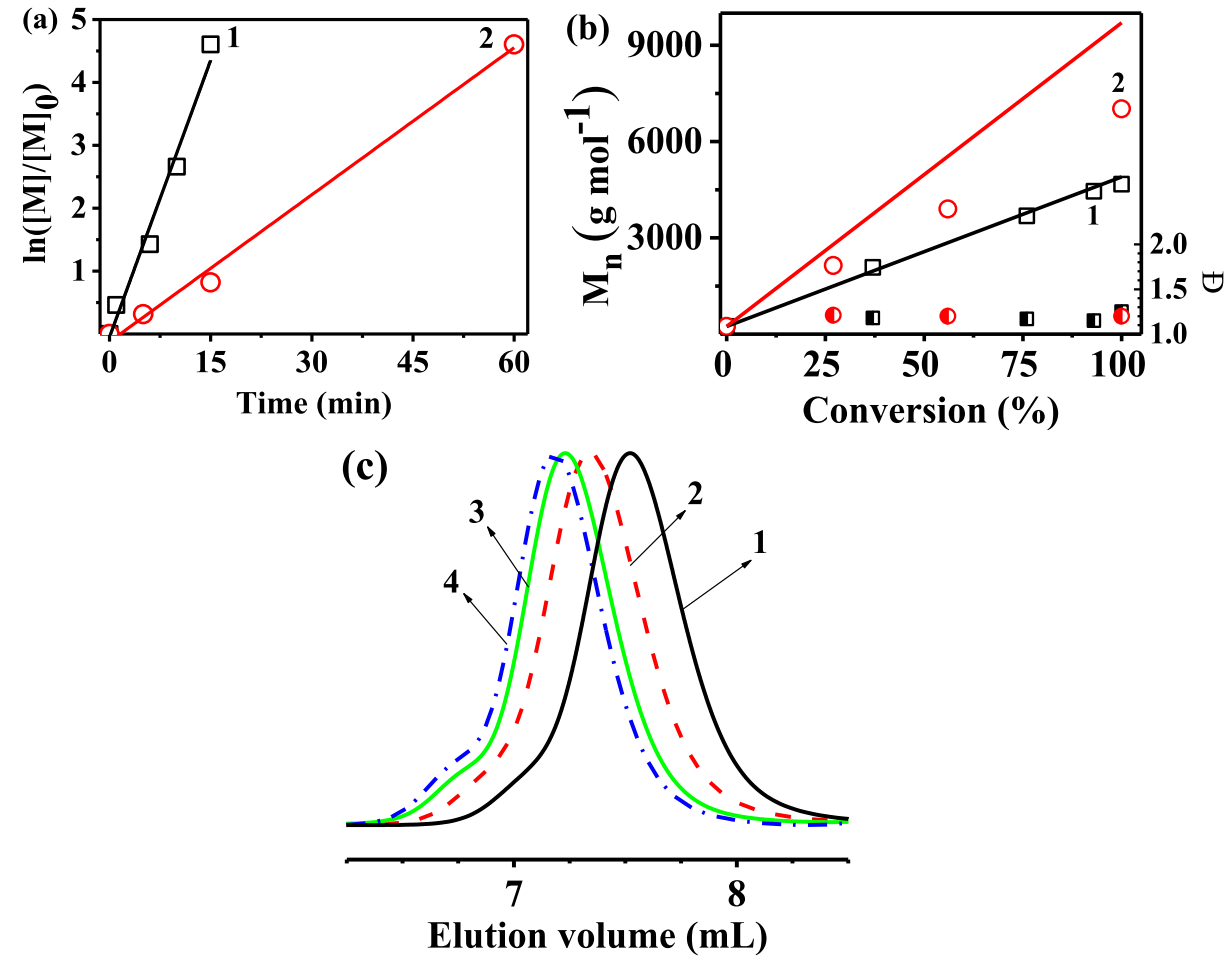

Fig. 1. (a) First-order plots, (b) $M_{n}, Ð$ vs. conversion plots for M1 polymerization using $\mathrm{C}_{6} \mathrm{H}_{13} \mathrm{SH} / \mathrm{TBD}$ initiating system at $20{ }^{\circ} \mathrm{C}$ in THF. Polymerization conditions: $[\mathrm{M} 1]=0.3 \mathrm{M},\left[\mathrm{C}_{6} \mathrm{H}_{13} \mathrm{SH}\right]=0.015 \mathrm{M}$, $[\mathrm{TBD}]=0.015 \mathrm{M} \quad(\mathbf{1}) ; \quad[\mathrm{M} 1]=0.3 \mathrm{M}, \quad\left[\mathrm{C}_{6} \mathrm{H}_{13} \mathrm{SH}\right]$ $=0.0075 \mathrm{M},[\mathrm{TBD}]=0.0075 \mathrm{M}$ (2). The straight lines in (b) correspond to theoretical $\mathrm{M}_{\mathrm{n}}$. (c) SEC traces of poly-(9-carbazolylmethyl)thiiranes at different monomer conversions (\%): 37 (1), 76 (2), 93 (3), 100 (4). 


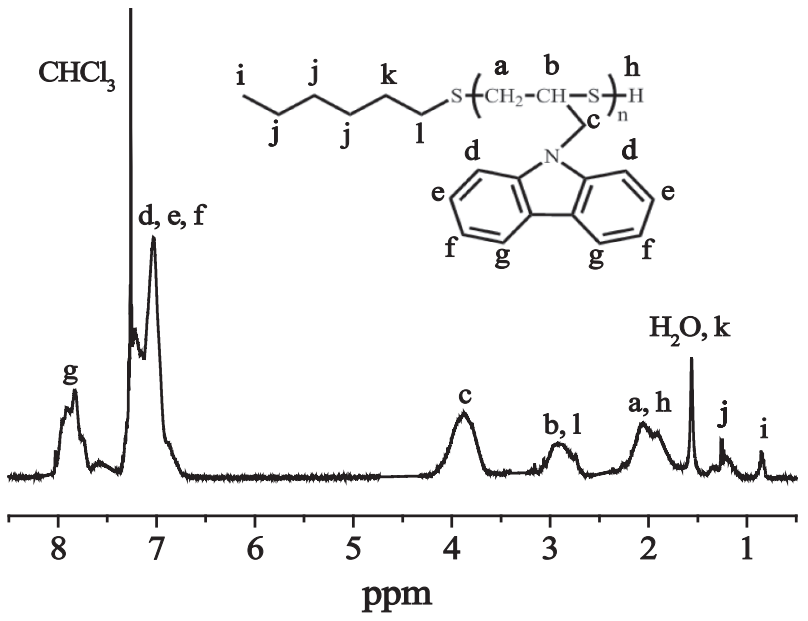

Fig. 2. ${ }^{1} \mathrm{H}$ NMR spectrum of the linear poly(9-carbazolylmethyl)thiirane synthesized with $\mathrm{C}_{6} \mathrm{H}_{13} \mathrm{SH} / \mathrm{TBD}$ initiating system (entry 2, Table 2).

\subsection{Synthesis of star-shaped polymers}

There are two main approaches for the star-shaped polymers synthesis: arm-first method [43-45] and core-first method [46-48]. In this work, star-shaped polythiiranes were synthesized by core-first method from M1 and M2 using tetrathiol PETMP as a multifunctional initiator and TBD as a co-initiator (Table 3).

According to Table 3, the number-average molecular weight of starshaped poly-(9-carbazolylmethyl)thiirane increases in direct proportion to $[\mathrm{M}] /[\mathrm{I}]$ ratio, while polydispersity remains relatively low $(\mathrm{D}<1.3$ ). However, the experimental values of $M_{n}$ determined by SEC against polystyrene standards are much lower in comparison with theoretical ones (Table 3). This discrepancy could be explained by known underestimation of molecular weight of star-shaped polymers measured by conventional SEC $[43,44]$. The use of ${ }^{1} \mathrm{H}$ NMR spectroscopy for determination of real number-average molecular weight of star-shaped poly-(9-carbazolylmethyl)thiirane, in contrast to linear counterpart (see Fig. 2 and discussion therein), is not applicable due to the overlapping of signals of protons of head and end groups with those of main chain (vide infra). Therefore, we used triple detection size exclusion chromatography to analyze some samples of star-shaped poly-(9-carbazolylmethyl)thiirane. Indeed, the number-average molecular weights determined by triple SEC are much higher than those obtained by conventional SEC and slightly higher than theoretical molecular weights (Table 3). Taking into account the more accurate determination of molecular weight by triple SEC, a calibration curve of $M_{n}$ (SEC) versus $\mathrm{M}_{\mathrm{n}}$ (triple detection) was constructed (Fig. S3) so as to correct
$M_{n}$ (SEC) values according to following equation: $M_{n}$ (corr.) $=2.35 \times \mathrm{M}_{\mathrm{n}}(\mathrm{SEC})+190$ (Table 3). The corrected values of $\mathrm{M}_{\mathrm{n}}$ were used further to construct $M_{n}$ versus conversion plots (Fig. 3b).

The first-order plots for the polymerization of M1 using PETMP/ TBD initiating system at different $[\mathrm{M}] /[\mathrm{I}]$ ratios are linear indicating the absence of irreversible termination (Fig. 3a). The number-average molecular weights increase in direct proportion to monomer conversion, while the experimental values of $\mathrm{M}_{\mathrm{n}}$ correlate well with theoretical ones for all $[\mathrm{M}] /[\mathrm{I}]$ ratios studied (Fig. $3 \mathrm{~b}$ ) indicating the absence of chain transfer during the synthesis of star-shaped polymers. The polydispersity is low $(\boxplus<1.3)$ and does not change with the monomer conversion for both of $[\mathrm{M}] /[\mathrm{I}]$ ratios studied (Fig. $3 \mathrm{~b}$ ). Moreover, the addition of the second portion of monomer after consuming of the first one results in doubling of $\mathrm{M}_{\mathrm{n}}$, while SEC trace completely shifts toward high molecular weight region (Fig. 3c). To summarize, the synthesis of star-shaped poly-(9-carbazolylmethyl)thiirane, similarly to synthesis of linear counterpart, proceeds in a living fashion. Then, the effect of [TBD]/[PETMP] ratio on the reaction rate as well as properties of the obtained star-shaped polymers were briefly investigated (Table S1, Fig. $\mathrm{S} 4)$. For $[\mathrm{M}] /[\mathrm{I}]=20$, the decrease of TBD to thiol ratio leads to the decrease of the reaction rate (Table 3, Fig. S4a), although the polydispersity and molecular weight are similar to those for polymer synthesized at $[\mathrm{TBD}] /[\mathrm{PETMP}]=4$ (Table $\mathrm{S} 1)$. However, the inspection of $\mathrm{M}_{\mathrm{n}}$ (corr.) versus conversion plots reveals the non-linearity of these dependences (Fig. S4b) indicating the occurrence of side reactions. Moreover, at higher monomer to initiator ratio $([\mathrm{M}] /[\mathrm{I}]=40)$, the significant increase of polydispersity is observed (Table S1). These results are consistent with slow and/or incomplete initiation when an excess of thiol over the co-initiator is used. Therefore, for the synthesis of well-defined star-shaped poly-(9-carbazolylmethyl)thiiranes, similarly to the preparation of linear polymers, the stoichiometric amount of TBD in respect to thiol group is required. Predictably the polymerization of M2 using PETMP/TBD initiating system proceeds at the lower rate than that of M1 (Table 3, Fig. S5a) as it was also observed for $\mathrm{C}_{6} \mathrm{H}_{13} \mathrm{SH} / \mathrm{TBD}$ initiating system.

Nevertheless, the first-order plot is linear for the polymerization of M2 with PETMP/TBD initiating system, while $\mathrm{M}_{\mathrm{n}} \mathrm{s}$ of the star-shaped poly-(3,6-di-tert-butyl-9-carbazolylmethyl)thiirane increase linearly with the increase of monomer conversion (Fig. S5a and S5b) and correlate well with the theoretical ones. In addition, the polydispersity does not change during the polymerization and remains relatively low (D < 1.35). Therefore, the polymerization of M2, similarly to polymerization of M1, proceeds in a living fashion.

The structure of the synthesized star-shaped polymer was investigated by NMR spectroscopy. ${ }^{1} \mathrm{H}$ NMR spectrum of star-shaped poly-(9-carbazolylmethyl)thiirane (Fig. S6) does not show any signals of protons of initiator fragment in a polymer chain indicating their overlapping with the signals of main chain protons. To confirm that and

Table 3

Polymerization of M1 using PETMP/TBD initiating system. ${ }^{\text {a }}$

\begin{tabular}{|c|c|c|c|c|c|c|c|c|c|}
\hline Entry & {$[\mathrm{M}] /[\mathrm{I}]$} & Time (min) & Conv (\%) & $\mathrm{M}_{\mathrm{n}}(\text { theor })^{\mathrm{b}}\left(\mathrm{g} \mathrm{mol}^{-1}\right)$ & $\mathrm{M}_{\mathrm{n}}(\mathrm{SEC})^{\mathrm{c}}\left(\mathrm{g} \mathrm{mol}^{-1}\right)$ & $\bigoplus^{\mathrm{c}}$ & $\mathrm{M}_{\mathrm{n}}(\mathrm{SEC})^{\mathrm{d}}\left(\mathrm{g} \mathrm{mol}^{-1}\right)$ & $\bigoplus^{\mathrm{d}}$ & $\mathrm{M}_{\mathrm{n}}(\text { corr. })^{\mathrm{e}}\left(\mathrm{g} \mathrm{mol}^{-1}\right)$ \\
\hline 1 & 15 & 0.2 & 100 & 4220 & 2300 & 1.21 & 5240 & 1.12 & 5600 \\
\hline 2 & 20 & 0.25 & 100 & 5300 & 2600 & 1.24 & 6830 & 1.12 & 6300 \\
\hline 3 & 40 & 4 & 100 & 10,100 & 3900 & 1.27 & 9700 & 1.14 & 9400 \\
\hline 4 & 60 & 15 & 100 & 14,830 & 7100 & 1.25 & - & - & 16,900 \\
\hline $5^{f}$ & 100 & 1 & 100 & 24,400 & 12,600 & 1.39 & - & - & 29,800 \\
\hline $6^{g}$ & 20 & 6 & 100 & 7500 & 4300 & 1.30 & - & - & 10,300 \\
\hline $7^{g}$ & 40 & 10 & 76 & 11,200 & 5400 & 1.34 & - & - & 12,900 \\
\hline
\end{tabular}

a Polymerization conditions: $[\mathrm{M}]=0.3 \mathrm{M}$; $[\mathrm{TBD}] /[\mathrm{PETMP}]=4$; solvent $-\mathrm{THF} ; \mathrm{T}=20^{\circ} \mathrm{C}$.

b Calculated with equation: $M_{n, \text { theor }}=M_{n}(M) \times\left([M]_{0} /[I]_{0}\right)+M_{n}(I)$.

c Determined by SEC in THF against polystyrene standards.

d Determined by triple detection size-exclusion chromatography in THF.

e $M_{n}$ (SEC) was corrected using the following equation: $M_{n}$ (corr.) $=2.35 \times M_{n}(S E C)+193$.

${ }^{f}$ DMF was used as a solvent.

g 3,6-Di-tert-butyl-9-(thiiran-2-ylmethyl)-9H-carbazole (M2) was polymerized. 

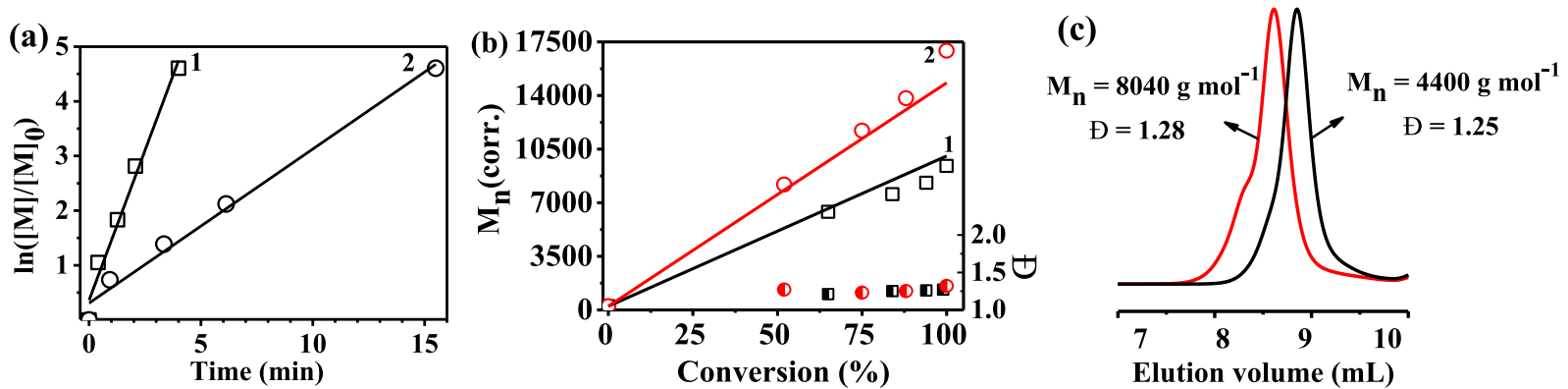

Fig. 3. (a) First-order plots, $\mathrm{M}_{\mathrm{n}}$ (corr.), (b) $Đ$ vs. conversion plots for $\mathbf{M} 1$ polymerization using PETMP/TBD initiating system at $20^{\circ} \mathrm{C}$ in THF. Polymerization conditions: $[\mathrm{M} 1]=0.3 \mathrm{M}$, [PETMP $]=0.0075 \mathrm{M}$, $[\mathrm{TBD}]=0.03 \mathrm{M}(1)$; $[\mathrm{M1}]=0.3 \mathrm{M}$, $[\mathrm{PETMP}]=0.005 \mathrm{M}$, $[\mathrm{TBD}]=0.02 \mathrm{M}(2)$. The straight lines in Fig. $3 \mathrm{~b}$ correspond to theoretical $\mathrm{M}_{\mathrm{n}}$. (c) SEC traces of star-shaped poly(9-(thiiran-2-ylmethyl)-9H-carbazoles before (1) and after (2) addition of second portion of monomer.

to identify the exact position of the signals of protons of head group, 2D HSQC $\left({ }^{1} \mathrm{H}\right.$-DEPT $\left.{ }^{13} \mathrm{C}\right)$ correlation NMR spectrum was recorded and analyzed (Fig. 4). Along with the signals of main chain protons (aliphatic $a-c(1.6-4.5 \mathrm{ppm})$ and aromatic $d-g(6.8-8.1 \mathrm{ppm})$ ), the signals of three groups of methylene protons $j, i$ and $h$ of tetrafunctional initiator were identified at $\{4.0-4.1 \times 62.5\} \mathrm{ppm},\{2.3-2.5 \times 36\} \mathrm{ppm}$ and $\{2.4-2.6 \times 29\} \mathrm{ppm}$ respectively. The signals of terminal monomer unit $k \quad(\{1.9-2.2 \times 38\} \quad \mathrm{ppm}), \quad l(\{3.1-3.3 \times 40\} \quad \mathrm{ppm})$ and $m$ $(\{3.9-4.1 \times 50\} \mathrm{ppm})$ can be also identified.

\subsection{End-capping with trifluoroacetic anhydride}

The synthesized poly-(9-carbazolylmethyl)thiiranes, especially starshaped polymers, are not stable under ambient conditions that leads to the appearance of shoulder in high molecular weight region in SEC chromatograms (Fig. 5a). The fraction of high molecular weight product increases with the increasing of storage time. This observation is consistent with high reactivity of thiol end groups leading to their oxidative coupling in the presence of oxygen [38].

It should be noted that this effect (oxidative coupling) is less pronounced in case of linear poly-(9-carbazolylmethyl)thiirane at room temperature, but becomes significant upon heating of polymer to $45^{\circ} \mathrm{C}$ (Fig. S7). The storage of polymer in refrigerator at $7{ }^{\circ} \mathrm{C}$ allows to suppress the oxidative chain coupling significantly (Figs. 5b and S8): only small shoulder is appeared in SEC curves during the storage for 15 months for both star-shaped (Fig. 5b) and linear (Fig. S8) polymers.

Another approach to protect synthesized polymers from oxidative coupling using in this work was end-capping of growing chains by trifluoroacetic anhydride (Scheme 1). Since ${ }^{1} \mathrm{H}$ NMR spectroscopy is not informative due to the overlapping of signals of protons of end group with those of main chain protons (Fig. 4), ${ }^{19} \mathrm{~F}$ NMR was recorded to confirm the efficiency of end-capping reaction (Fig. S9). The protected star-shaped polymers were additionally analyzed by SEC method (Fig. 5c): the shape of SEC curves does not change even after heating of polymer at $45^{\circ} \mathrm{C}$ during one week in air. These results suggest about high efficiency of protection of thiol end groups from oxidative coupling by end-capping with trifluoroacetic anhydride. The high reactivity of thiol end group towards nucleophilic substitution demonstrated here opens an access to functionalization of star-shaped poly-(9carbazolylmethyl)thiirane with different functional groups (for example (meth)acrylate group) to prepare cross-linkable polymers.

\subsection{Properties}

The thermal properties of monomers (M1, M2) and the synthesized linear (LP1, LP2) and star-shaped polymers (SP1, SP2) were studied by DSC and TGA. The values of melting points $\left(\mathrm{T}_{\mathrm{m}}\right)$, glass transition temperatures $\left(\mathrm{T}_{\mathrm{g}}\right)$, and temperatures at which $5 \%$ loss of mass $\left(\mathrm{T}_{\mathrm{ID}}\right)$ were observed are summarized in Table 4, Figs. S10 and S11. All the synthesized polymers demonstrated relatively high thermal stability. The values of polymers $\mathrm{T}_{\mathrm{ID}}$ were found to be about $300^{\circ} \mathrm{C}$ as confirmed by TGA at the heating rate of $20^{\circ} \mathrm{C} / \mathrm{min}$. The lower thermal stability of the monomers relative to that of the corresponding polymers can be explained by the presence of the reactive vinyl group and by the lower intermolecular interactions. M2, which contains 3,6-di-tert-butyl substituted carbazole groups, exhibits higher $\mathrm{T}_{\mathrm{ID}}$ than the monomer having unsubstituted carbazole groups, apparently, due to the enhanced intermolecular interactions [2].

The monomers M1 and M2, which were crystalline materials, showed endothermic melting signals in the first heating scans at 104 and $137^{\circ} \mathrm{C}$, respectively. Monomer $\mathbf{M} 2$ can be also transformed into the glassy state $\left(\mathrm{T}_{g}=37^{\circ} \mathrm{C}\right)$ by cooling from the melt as it was shown recently [2]. Glass transition temperatures $\left(\mathrm{T}_{\mathrm{g}}\right)$ for LP1 and SP1 were found to be higher than $\mathrm{T}_{\mathrm{m}}$ of the corresponding monomers. Polymers were isolated as amorphous materials. No peaks due to crystallization and melting in their DSC scans were observed and only glass transitions could be noticed there. The glass transition temperature of LP2 is higher than that of LP1 due to the presence of more bulky substituent in a monomer unit. In addition, the glass transition temperature of the star-shaped polymers was found to be lower than of their linear counterparts (Table 4) that is correlated well with the literature data [49].

Absorption and fluorescence spectra of dilute THF solutions of polymers were recorded to determine absorption and fluorescence maxima (Table 4, Figs. S12 and S13). Maxima of absorption spectra are almost identical for all polymers, but slight absorption shift for LP2 and SP2 can be attributed to the slightly different steric environment due to the presence of substituents in the carbazole ring. Fluorescence spectra give two maxima for all linear and star-shaped polymers: $351,364 \mathrm{~nm}$ for LP1 and SP1, 360, $372 \mathrm{~nm}$ for LP2 and 358, $372 \mathrm{~nm}$ for SP2, respectively (Table 4). There is no significant difference in the photophysical properties between linear and star-shaped polymers.

To estimate the energetic conditions for energy and electron transfer under diluted conditions, the ionization potentials $\left(\mathrm{I}_{\mathrm{p}(\mathrm{CV})}\right)$ and electron affinities $\left(\mathrm{E}_{\mathrm{A}(\mathrm{CV})}\right)$ of the linear and star shaped polymers of different molecular weight were established by cyclic voltamperometry (Table 5).

Cyclic voltammograms of linear and star-shaped polymers have the similar shape (some difference is observed for LP2 and SP2) and show quasi-reversible oxidation (Fig. 6). Ionization potentials established by cyclic voltamperometry $\left(\mathrm{I}_{\mathrm{p}(\mathrm{CV})}\right)$ of $\mathbf{L P 1}$ and SP1 are comparable (5.24-5.34 eV and $5.30 \mathrm{eV}$, respectively), while some difference was observed for LP2 and SP2 (5.66 and $5.26 \mathrm{eV}$, respectively) (Table 5). The electron affinity $\left(\mathrm{E}_{\mathrm{A}(\mathrm{CV})}\right)$ values of the polymers show the same tendency as $\mathrm{I}_{\mathrm{p}(\mathrm{CV})}$ values. Interestingly, both $\mathrm{I}_{\mathrm{p}(\mathrm{CV})}$ and $\mathrm{E}_{\mathrm{A}(\mathrm{CV})}$ of poly-(9carbazolylmethyl)thiirane increase with increasing molecular weight of polymer (Table 5). 

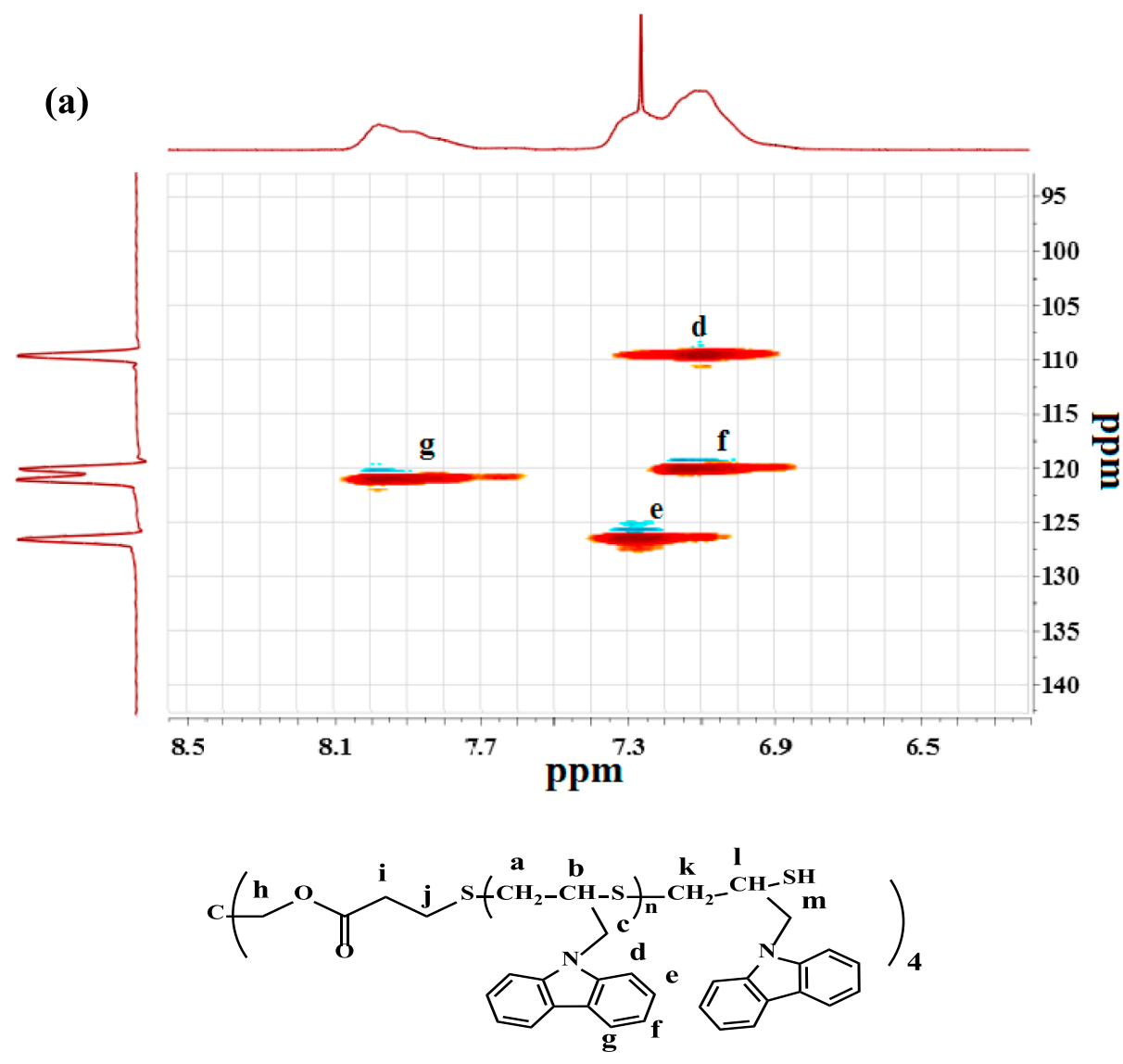

(b)

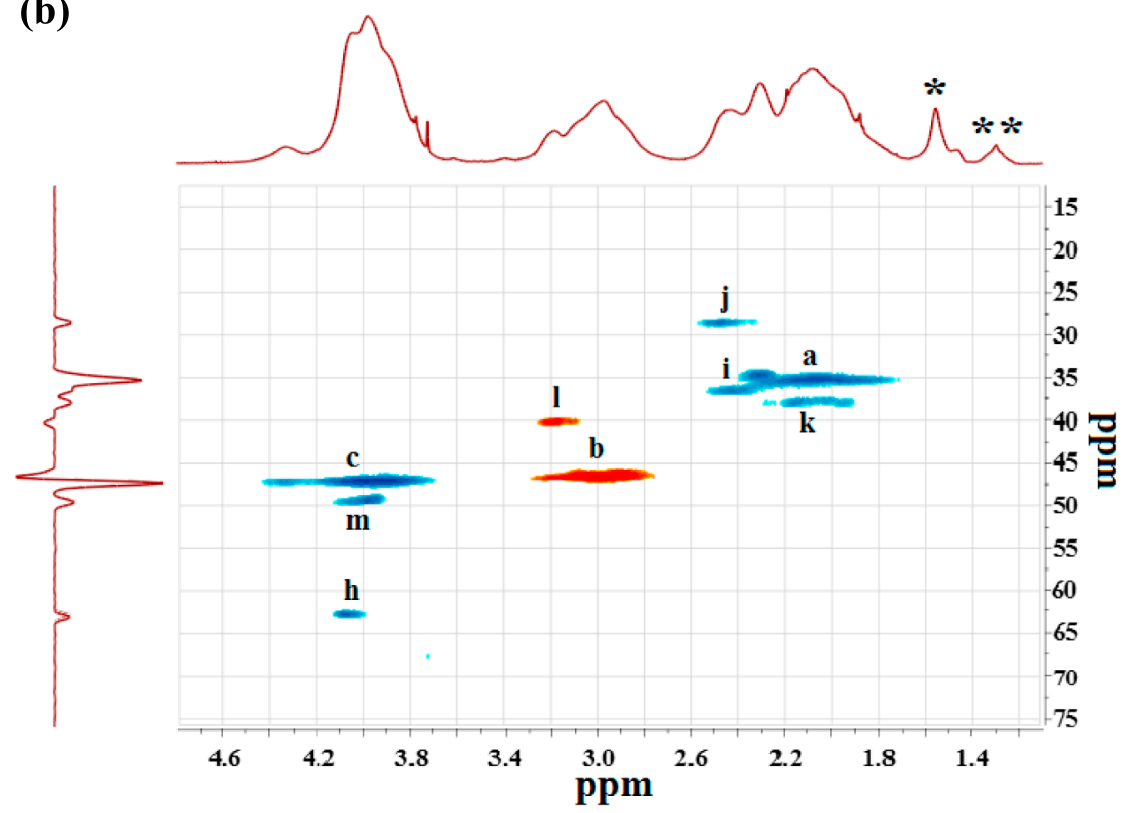

Fig. 4. Aromatic (a) and aliphatic (b) parts of HSQC $\left({ }^{1} \mathrm{H}\right.$-DEPT $\left.{ }^{13} \mathrm{C}\right)$ NMR spectrum of the star-shaped poly-(9-carbazolylmethyl)thiirane synthesized with PETMP/ TBD initiating system (entry 3 , Table 3 ). * - water, ** - grease.

\section{Experimental}

\subsection{Materials}

THF (Sigma-Aldrich, $\geq 99 \%$ ) was treated with $\mathrm{KOH}$ and distilled twice from Na under an inert atmosphere. DMF (Sigma-Aldrich, $\geq 99.8 \%$ ) was distilled from $\mathrm{CaH}_{2}$ under reduced pressure. 1,5,7Triazabicyclo[4.4.0]dec-5-ene (Sigma-Aldrich, $\geq 98 \%$ ) was vacuum dried at room temperature before use. Pentaerythritol tetrakis(3-mercaptopropionate) (Sigma-Aldrich, $\geq 95 \%$ ), trifluoroacetic anhydride (Sigma-Aldrich, $\geq 99 \%$ ), $\mathrm{CDCl}_{3}$ (Euriso-top ${ }^{\circledR}$ ) and ethanol (96\%) were used as received. 1-Hexanethiol [50] and monomers (9- 

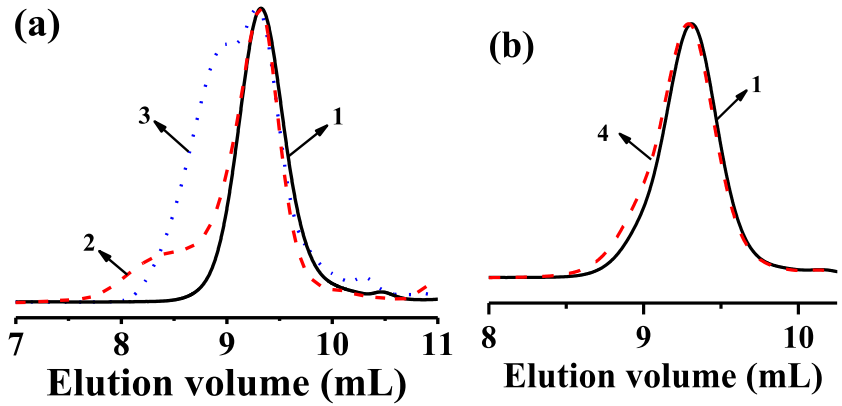

Table 4

Thermal and photophysical characteristics of monomers and synthesized linear and star-shaped polymers.

\begin{tabular}{lllllll}
\hline Compound & $\mathrm{M}_{\mathrm{n}}\left(\mathrm{g} \mathrm{mol}{ }^{-1}\right)$ & $\mathrm{T}_{\mathrm{m}}{ }^{\mathrm{a}}\left({ }^{\circ} \mathrm{C}\right)$ & $\mathrm{T}_{\mathrm{g}}{ }^{\mathrm{a}}\left({ }^{\circ} \mathrm{C}\right)$ & $\mathrm{T}_{\mathrm{ID}}{ }^{\mathrm{c}}\left({ }^{\circ} \mathrm{C}\right)$ & $\lambda^{\mathrm{d}, \mathrm{e}}(\mathrm{nm})$ & $\lambda^{\mathrm{d}, \mathrm{f}}(\mathrm{nm})$ \\
\hline M1 & 239 & 106 & - & 234 & - & - \\
LP1 & 6000 & - & 122 & 298 & 343 & $351 ; 364$ \\
SP1 & 10,000 & - & 117 & 298 & 343 & $351 ; 364$ \\
M2 & 351 & 137 & 37 & 283 & - & - \\
LP2 & 5400 & - & 148 & 299 & 349 & $360 ; 372$ \\
SP2 & 10,500 & - & $94^{\mathrm{b}}$ & 294 & 349 & $358 ; 372$ \\
\hline
\end{tabular}

a Determined by DSC from second heating scan: scan rate $20^{\circ} \mathrm{C} / \mathrm{min} ; \mathrm{N}_{2}$ atmosphere.

b Determined by DSC from second heating scan: scan rate $30^{\circ} \mathrm{C} / \mathrm{min} ; \mathrm{N}_{2}$ atmosphere.

c $5 \%$ weight loss determined by TGA: heating rate $20^{\circ} \mathrm{C} / \mathrm{min} ; \mathrm{N}_{2}$ atmosphere.

d Absorption and fluorescence $\left(\lambda_{\text {exc }}=310 \mathrm{~nm}\right)$ spectra were recorded of dilute THF solutions $\left(10^{-4} \mathrm{~mol} / \mathrm{L}\right)$ of the polymers.

e Absorption maxima.

f Fluorescence maxima.

Table 5

Electrochemical parameters of the linear and star-shaped polymers.

\begin{tabular}{llllll}
\hline Compound & $\begin{array}{l}\mathrm{M}_{\mathrm{n}, \mathrm{SEC}} \\
\left(\mathrm{g} \mathrm{mol}^{-1}\right)\end{array}$ & $\begin{array}{l}\mathrm{E}_{\text {onset }}^{\text {ox }} \mathrm{Vs} \mathrm{Fc} \\
(\mathrm{V})\end{array}$ & $\mathrm{E}_{\mathrm{g}}^{\mathrm{optb}}(\mathrm{eV})$ & $\mathrm{I}_{\mathrm{p}(\mathrm{CV})}{ }^{\mathrm{c}}(\mathrm{eV})$ & $\mathrm{E}_{\mathrm{A}(\mathrm{CV})}{ }^{\mathrm{c}}(\mathrm{eV})$ \\
\hline LP1 & 4400 & 0.92 & 3.53 & 5.24 & 1.71 \\
LP1 & 5800 & 0.94 & 3.53 & 5.26 & 1.73 \\
LP1 & 7800 & 1.02 & 3.53 & 5.34 & 1.81 \\
SP1 & 10,000 & 0.98 & 3.53 & 5.30 & 1.77 \\
LP2 & 5400 & 1.34 & 3.46 & 5.66 & 2.20 \\
SP2 & 10,500 & 0.94 & 3.46 & 5.26 & 1.80 \\
\hline
\end{tabular}

a The onset oxidation potentials with respect to ferrocene measured by CV from the first redox cycle.

$\mathrm{b}$ The optical band gaps estimated from the edges of electronic absorption spectra.

c Ionization potentials and electron affinities obtained by $\mathrm{CV}$ data according to the equations: $\mathrm{I}_{\mathrm{P}(\mathrm{CV})}=4.8+\mathrm{E}_{\text {onset }}^{\text {ox }} \mathrm{vs} \mathrm{Fc}$ and $\mathrm{E}_{\mathrm{A}(\mathrm{CV})}=\mathrm{I}_{\mathrm{P}(\mathrm{CV})}-\mathrm{E}_{\mathrm{g}}^{\mathrm{opt}}$.

carbazolylmethyl)thiirane (M1) and (3,6-di-tert-butyl-9-carbazolylmethyl)thiirane (M2)) [2] were synthesized according to the literature procedures.

\subsection{Instrumentation}

Size exclusion chromatography (SEC) was performed on an Ultimate 3000 Thermo Scientific apparatus with Agilent PLgel $5 \mu \mathrm{m}$ MIXED-C $(300 \times 7.5 \mathrm{~mm}$ ) column and one precolumn (PLgel $5 \mu \mathrm{m}$ guard $50 \times 7.5 \mathrm{~mm}$ ) thermostated at $30^{\circ} \mathrm{C}$. The detection was achieved by differential refractometer (thermostated at $35^{\circ} \mathrm{C}$ ). Tetrahydrofuran (THF) was eluted at a flow rate of $1.0 \mathrm{~mL} / \mathrm{min}$. The calculation of molar mass and polydispersity was carried out using polystyrene standards (Polymer Labs, Germany). Molecular weights of the star-shaped

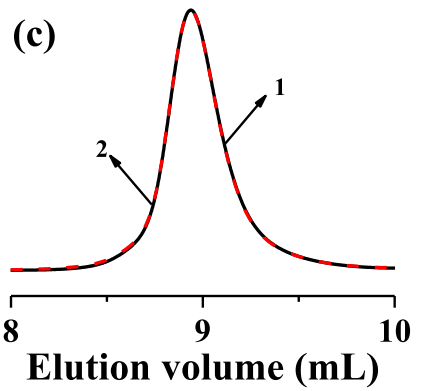

Fig. 5. SEC curves of (a, b) unprotected starshaped poly(9-carbazolylmethyl)thiiranes just after polymerization (1); after storage for 10 days (2) and for 15 months (3) under an air atmosphere at r.t.; after storage for 15 months under air atmosphere at $7{ }^{\circ} \mathrm{C}$ (4) and (c) protected star-shaped poly(9-carbazolylmethyl)thiirane before (1) and after (2) storage for 1 week under an air atmosphere at $45^{\circ} \mathrm{C}$. polymers were also determined using Agilent Technologies 1260 Infinity chromatograph (the Agilent 1260 Infinity Multi-Detector GPC/ SEC System), equipped with differential refractometer (DRI, wavelength $660 \mathrm{~nm}$ ), viscosimetric (VS), and light-scattering (LS) detectors (Rayleigh scattering angles $15^{\circ}$ and $90^{\circ}$; laser wavelength/power $660 \mathrm{~nm} / 50 \mathrm{~mW}$ ) at the temperatures of $40^{\circ} \mathrm{C}$. The setup included a set of sequentially connected columns: a precolumn PLgel $5 \mu \mathrm{m}$ guard $50 \times 7.5 \mathrm{~mm}$ and two styragel columns Agilent Technologies PLgel $5 \mu \mathrm{m}$ MIXED-C, $300 \times 7.5 \mathrm{~mm}$. The mobile phase is tetrahydrofuran. The mobile phase flow rate is $1.0 \mathrm{~mL} / \mathrm{min}$. The absolute molecular weight and molecular-weight distribution were calculated using ASTRA for Windows (Version 7.1.0.29) with known specific refractive index increment $(\mathrm{dn} / \mathrm{dc})$ and known RI detector calibration constant. The $\mathrm{dn} /$ dc of 0.1766 was obtained from the slope of plot $\Delta \mathrm{n} \sim$ concentration. ${ }^{1} \mathrm{H}(500 \mathrm{MHz})$ and ${ }^{1} \mathrm{H}$ \{DEPT ${ }^{13} \mathrm{C}$ \} HSQC NMR spectra were recorded in $\mathrm{CDCl}_{3}$ at $25^{\circ} \mathrm{C}$ on a Brucker AC- 500 spectrometer calibrated relative to the solvent peaks. Differential scanning calorimetry (DSC) measurements were carried out using a DSC Q2000 thermal analyzer at a heating rate of $20^{\circ} \mathrm{C} / \mathrm{min}$ under nitrogen flow. Thermogravimetric analysis (TGA) was performed on a TGA Q50 apparatus. Absorption and fluorescence spectra were recorded on Perkin Elmer Lambda 35 spectrometer. For these measurements, the dilute solutions of the investigated compounds were prepared by dissolving them in a spectral grade THF at $10^{-4} \mathrm{M}$ concentration.

Cyclic voltammetry (CV) measurements were carried out using a three-electrode assembly cell from Bio-Logic SAS and a microAUTOLAB Type III potentiostat-galvanostat. The measurements were carried out with a glassy carbon electrode, $\mathrm{Ag} / \mathrm{AgNO}_{3}$ as the reference electrode and a Pt wire as the counter electrode in dichloromethane solutions containing $0.1 \mathrm{M}$ tetrabutylammonium perchlorate as the electrolyte. The $E_{\text {Hомо }}$ energy values of the compounds were determined from oxidation potentials, taking the value of $-4.8 \mathrm{eV}$ as the $E_{\text {Hомо }}$ energy level for ferrocene (Fc) with respect to the zero vacuum level [2]. Ionization potentials (Ip) of the films of the synthesized compounds were measured by the electron photoemission in air method as described before [2].

\subsection{Polymerization procedure}

Polymerization was carried out under dry argon atmosphere in a Schlenk tube. Liquid reagents were transferred to reactor via dry syringes against a continuous argon flow. The reaction was initiated by adding a $0.1 \mathrm{M}$ solution of TBD in THF $(0.052 \mathrm{~mL})$ to a mixture of (9carbazolylmethyl)thiirane $(0.050 \mathrm{~g})$, THF $(0.593 \mathrm{~mL})$ and $0.1 \mathrm{M}$ solution of $\mathrm{C}_{6} \mathrm{H}_{13} \mathrm{SH}$ in THF $(0.052 \mathrm{~mL})$ at room temperature. After a predetermined time, $\sim 0.15 \mathrm{~mL}$ aliquots were withdrawn and poured into excess of ethanol. The precipitated polymers were separated from the solution by centrifugation and then dried in vacuum at $40^{\circ} \mathrm{C}$. Monomer conversions were determined gravimetrically. For further analyses polymers were dissolved in $\mathrm{CHCl}_{3}$ and precipitated in an excess of ethanol and then dried in vacuum. 

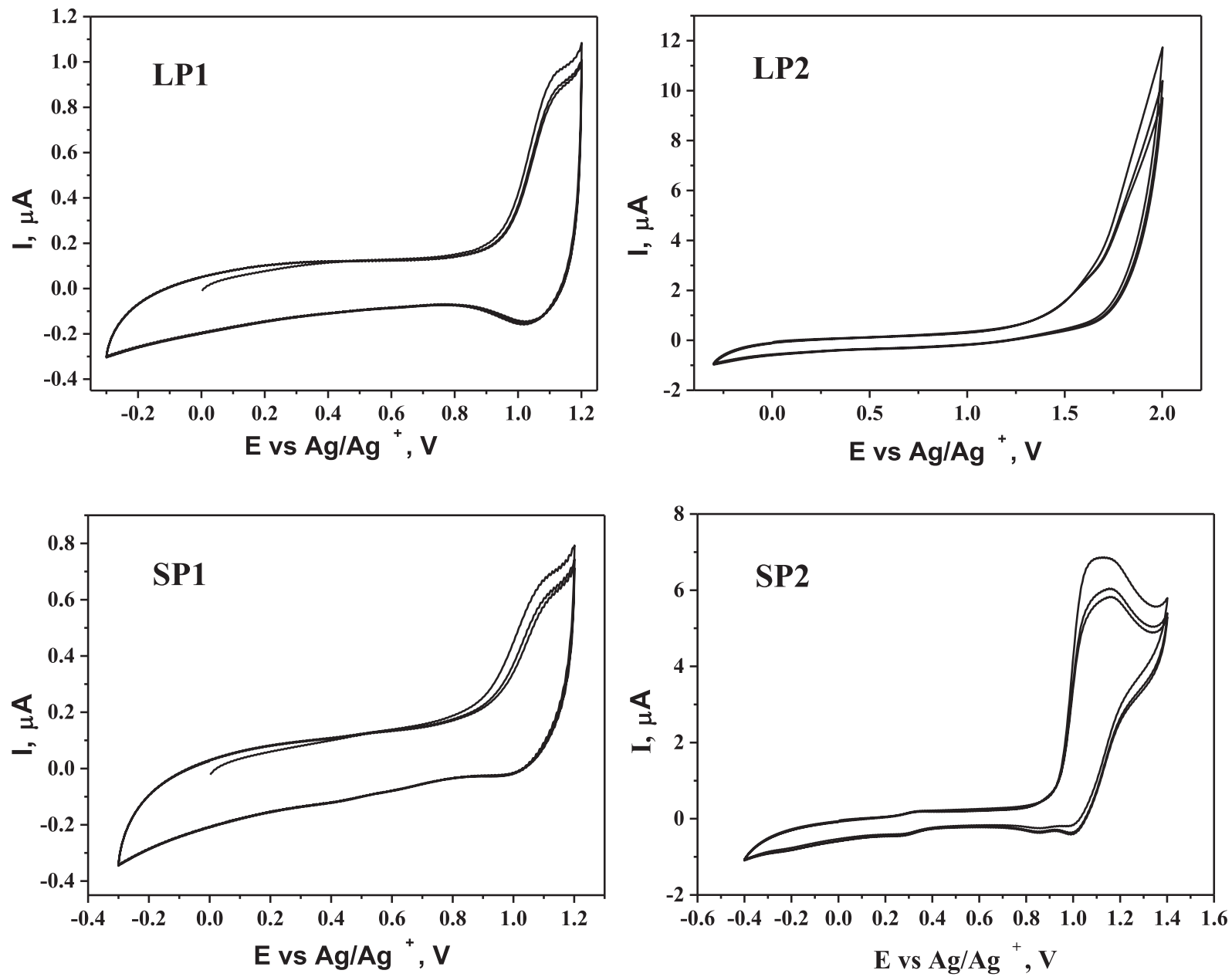

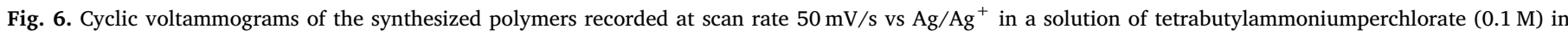
$\mathrm{CH}_{2} \mathrm{Cl}_{2}$.

\subsection{DFT calculations}

All calculations were performed as described [15]. All optimized structures were checked to be minima, with no imaginary frequencies. The solvent effects were evaluated using the polarized continuum model (PCM) with the default parameters for tetrahydrofuran. The parameter values used for describing dimethylformamide are as follows: $\mathrm{EPS}=36.71$, RSOLV $=2.647$, density $=0.007777$, and $\mathrm{EP}$ SINF $=2.039[51]$.

\section{Conclusions}

In this work, the organocatalytic controlled anionic ring-opening polymerization of two carbazole-containing thiirane derivatives (9carbazolylmethyl)thiirane (M1) and (3,6-di-tert-butyl-9-carbazolylmethyl)thiirane (M2) was performed for the first time. An initiating system based on thiol as an initiator and 1,5,7-triazabicyclo[4.4.0]dec5-ene (TBD) as catalyst induced fast living polymerization of both monomers at room temperature to afford linear polymers with molecular weight in the range of $M_{n}=4000-15000 \mathrm{~g} \mathrm{~mol}^{-1}$ and relatively low polydispersity $(\boxplus<1.3$ ). It was demonstrated that the stoichiometric amount of TBD towards thiol is required in order to provide the livingness of the polymerization process. The star-shaped polymers with controlled molecular weight $\left(M_{n}=5000-17000 \mathrm{~g} \mathrm{~mol}^{-1}\right)$ were then synthesized under optimal conditions developed for linear polymers. It was demonstrated that end-capping of polymers by trifluoroacetic anhydride allowed to protect thiol end groups from oxidative coupling. The high reactivity of thiol end group towards nucleophilic substitution demonstrated here opens an access to functionalization of star-shaped poly-(9-carbazolylmethyl)thiirane with different functional groups (for example (meth)acrylate group) to prepare cross-linkable polymers. The thermal, photophysical and electrochemical properties of the synthesized linear and star-shaped polymers were estimated. It was demonstrated that synthesized polymers are promising host materials for solution processable polymeric light emitting devices.

\section{Acknowledgements}

This work was supported by European Union's Horizon 2020 Research and Innovation Programme under the Marie SkłodowskaCurie grant agreement No 823720 .

\section{Appendix A. Supplementary material}

Tables with polymerization data, NMR spectra, SEC traces, DSC curves, absorption and fluorescence spectra, $\ln \left([\mathrm{M}] /[\mathrm{M}]_{0}\right)$ vs. time and $\mathrm{M}_{\mathrm{n}}$, (D) vs. conv. curves. The raw/processed data required to reproduce these findings cannot be shared at this time due to technical or time limitations. Supplementary data to this article can be found online at https://doi.org/10.1016/j. eurpolymj.2019.05.009. 


\section{References}

[1] (a) J.V. Grazulevicius, P. Strohriegl, J. Pielichowski, K. Pielichowski, Carbazolecontaining polymers: synthesis, properties and applications, Prog. Polym. Sci. 28 (2003) 1297-1353;

(b) K.P. Bhuvana, R.J. Bensingh, M.A. Kader, S.K. Nayak, Polymer light emitting diodes: materials, technology and device, Polym. Plast. Technol. Eng. 57 (2018) 1784-1800;

(c) J. Lia, A.C. Grimsdale, Carbazole-based polymers for organic photovoltaic devices, Chem. Soc. Rev. 39 (2010) 2399-2410;

(d) A.C. Grimsdale, K.L. Chan, R.E. Martin, P.G. Jokisz, A.B. Holmes, Synthesis of light-emitting conjugated polymers for applications in electroluminescent devices, Chem. Rev. 109 (2009) 897-1091.

[2] E. Stanislovaityte, J. Simokaitiene, S. Raisys, H. Al-Attar, J.V. Grazulevicius, A.P. Monkman, V. Jankus, Carbazole based polymers as hosts for blue iridium emitters: synthesis, photophysics and high efficiency PLEDs, J. Mater. Chem. 1 (2013) 8209-8221.

[3] H. Tang, Y. Li, B. Chen, H. Wu, W. Yang, Y. Cao, A novel heteroleptic iridium complex with multifunctional ligands used for polymeric light-emitting diodes, Opt. Mater. 33 (2011) 1291-1296.

[4] M. Zhu, Y. Li, C. Li, C. Zhong, C. Yang, H. Wu, J. Qin, Y. Cao, Tuning the energy levels and photophysical properties of triphenylamine-featured iridium(III) complexes: application in high performance polymer light-emitting diodes, J. Mater. Chem. 22 (2012) 11128-11133.

[5] K. Nakabayashi, H. Mori, Novel complex polymers with carbazole functionality by controlled radical polymerization, Int. J. Polym. Sci. 2012 (2012) 1-18.

[6] K. Nakabayashi, H. Mori, Recent progress in controlled radical polymerization of Nvinyl monomers, Eur. Polym. J. 49 (2013) 2808-2838.

[7] C.F. Huang, Y.A. Hsieh, S.C. Hsu, K. Matyjaszewski, Synthesis of poly(N-vinyl carbazole)-based block copolymers by sequential polymerizations of RAFT-ATRP, Polymer 55 (2014) 6051-6057.

[8] C.J. Hu, R. Oshima, S. Sato, M. Seno, Synthesis and photoinduced discharge characteristics of polyacrylates with pendant carbazole group, J. Polym. Sci. Part C: Polym. Lett. 26 (1988) 441-446.

[9] M. Keyanpour-Rad, A. Ledwith, A. Hallam, A.M. North, M. Breton, C. Hoyle J.E. Guillet, Some photophysical properties of five new carbazole-containing me thacrylate polymers, Macromolecules 11 (1978) 1114-1118.

[10] F.S. Du, Z.C. Li, W. Hong, Q.Y. Cao, F.M. Li, Vinyl monomers bearing chromophore moieties and their polymers. XI. Synthesis and photochemical behavior of carbazole-containing methacrylic monomers and their polymers, J. Polym. Sci. Part A Polym. Chem. 38 (2000) 679-688.

[11] S. Barik, S. Valiyaveettil, Synthesis and self-assembly of copolymers with pendant electroactive units, Macromolecules 41 (2008) 6376-6386.

[12] T. Kanbara, Y. Yokokawa, K. Hasegawa, Palladium-catalyzed modification of poly (p-bromostyrene) with carbazole and related heteroarenes containing an $\mathrm{N}-\mathrm{H}$ bond and their properties, J. Polym. Sci. Part A: Polym. Chem. 38 (2000) 28-34.

[13] T. Uryu, H. Ohkawa, R. Oshima, Synthesis and high hole mobility of isotactic poly (2-N-carbazolylethyl acrylate), Macromolecules 20 (1987) 712-716.

[14] Y.S. Cho, S.W. Kim, C.S. Ihn, J.S. Lee, Anionic polymerization of 4-(9-carbazolyl) methylstyrene, Polymer 42 (2001) 7611-7616.

[15] I.V. Vasilenko, A.A. Vaitusionak, J. Sutaite, A. Tomkeviciene, J. Ostrauskaite, J.V. Grazulevicius, S.V. Kostjuk, Simultaneous step-growth and chain-growth cationic polymerization of styrenic monomers bearing carbazolyl groups, Polymer 129 (2017) 83-91.

[16] H. Mori, H. Ookuma, S. Nakano, T. Endo, Xanthate-mediated controlled radica polymerization of N-vinylcarbazole, Macromol. Chem. Phys. 207 (2006) 1005-1017.

[17] J.D. Quinn, R.A. Register, Nitroxide-mediated radical polymerization of N-ethyl-2vinylcarbazole, Polym. Adv. Technol. 19 (2008) 556-559.

[18] H. Mori, S. Nakano, T. Endo, Controlled synthesis of poly(N-ethyl-3-vinylcarbazole) and block copolymers via RAFT polymerization, Macromolecules 38 (2005) $8192-8201$.

[19] W.Y. Tam, C.S.K. Mak, A.M.C. Ng, A.B. Djurisic, W.K. Chan, Multifunctional poly(Nvinylcarbazole)-based block copolymers and their nanofabrication and photosensitizing properties, Macromol. Rapid Commun. 30 (2009) 622-626.

[20] C.F. Huang, J.A. Yoon, K. Matyjaszewski, Synthesis of N-vinylcarbazole-N-vinylpyrrolidone amphiphilic block copolymers by xanthate-mediated controlled radical polymerization, Can. J. Chem. 88 (2010) 228-235.

[21] H. Mori, S. Okabayashi, Synthesis, assembled structure, and chiroptical properties of amino acid-based amphiphilic block copolymers containing carbazole moiety, React. Funct. Polym. 69 (2009) 441-449.

[22] H. Mori, H. Ookuma, T. Endo, Poly(N-vinylcarbazole) star polymers and amphiphilic star block copolymers by xanthate-mediated controlled radical polymerization, Macromolecules 41 (2008) 6925-6934.

[23] W. Zhang, Y. Yan, N. Zhou, Z. Cheng, J. Zhu, C. Xia, X. Zhu, Controlled synthesis and fluorescent properties of poly(9-(4-vinylbenzyl)-9H-carbazole) via nitroxidemediated living free-radical polymerisation, Eur. Polym. J. 44 (2008) 3300-3305.

[24] B. Lessard, E.J.Y. Ling, M.S.T. Morin, M. Maric, Nitroxide-mediated radical copolymerization of methyl methacrylate controlled with a minimal amount of 9-(4vinylbenzyl)-9H-carbazole, J. Polym. Sci. Part A: Polym. Chem. 49 (2011) 1033-1045.

[25] P. Zhao, Q.D. Ling, W.Z. Wang, J. Ru, S.B. Li, W. Huang, Reversible additionfragmentation chain transfer polymerization of methacrylates containing hole- or electron-transporting groups, J. Polym. Sci. Part A: Polym. Chem. 45 (2007)
$242-252$.

[26] D. Neugebauer, D. Charasim, A. Swinarew, A. Stolarzewicz, M. Krompiec, H. Janeczek, J. Simokaitiene, J.V. Grazulevicius, Polymethacrylates with anthryl and carbazolyl groups prepared by atom transfer radical polymerization, Polym. J. 43 (2011) 448-454.

[27] C. Ulbricht, C.R. Becer, A. Winter, D. Veldman, U.S. Schubert, Copolymers containing phosphorescent iridium(III) complexes obtained by free and controlled radical polymerization techniques, Macromol. Rapid Commun. 29 (2008) 1919-1925.

[28] J.V. Grazulevicius, R. Kublickas, Polymerization of carbazolyl-containing epoxides by activated monomer mechanism, Eur. Polym. J. 27 (1991) 1411-1416.

[29] V. Andruleviciute, R. Lazauskaite, J.V. Grazulevicius, A. Stanisauskaite, Cationic photopolymerization of carbazolyl- and phenothiazinyl-containing thiiranes, J. Photochem. Photobiol, A: Photochem. 147 (2002) 63-69.

[30] G. Buika, J.V. Grazulevicius, Polymerization of 9-(2,3-epoxypropyl)carbazole with complexes of potassium compounds and 18-crown-6, Eur. Polym. J. 29 (1993) 1489-1493.

[31] K.M. Akhmedov, K.S. Karimov, I.M. Scherbakova, Y.N. Porschnev, M.I. Cherkashin, The synthesis and properties of $\mathrm{N}$-(2,3-epoxypropyl)carbazoles and the oligomers based on them, Russ. Chem. Rev. 59 (1990) 425-439.

[32] J.V. Grazulevicius, A. Stanisauskaite, V. Gaidelis, A. Undzenas, USSR Patent. 670 123.

[33] S. Boileau, G. Champetier, P. Sigwalt, Polymerisation anionique du sulfure de propylene, Makromolek. Chem. 69 (1963) 180-192.

[34] A. Nicco, B. Boucheron, Polymerisation anionique des thiirannes, Eur. Polym. J. 6 (1970) 1477-1490.

[35] P. Guerin, S. Boileau, F. Subira, P. Sigwalt, Polymerisation en phase homogene du methyl-2 thiiranne amorcee par les thiolates de cadmium et de zinc. Influence de interactions monomere-metal sur la stereoregularite des polymers, Eur. Polym. J. 16 (1980) 121-128.

[36] C. Bonnans-Plaisance, P. Guerin, G. Levesque, Preparation and characterization of poly(thiirane) block copolymers with pendent hydroxy groups, Polymer 36 (1995) 201-208.

[37] E. Nicol, C. Bonnans-Plaisance, G. Levesque, A New initiator system for the living thiiranes ring-opening polymerization: a way toward star-shaped polythiiranes, Macromolecules 32 (1999) 4485-4487.

[38] E. Nicol, C. Bonnans-Plaisance, P. Dony, G. Levesque, Synthesis of end-functionalized star-shaped poly(methylthiirane)s, Macromol. Chem. Phys. 202 (2001) 2843-2852.

[39] B.G.G. Lohmeijer, R.C. Pratt, F. Leibfarth, J.W. Logan, D.A. Long, A.P. Dove, F. Nederberg, J. Choi, C. Wade, R.M. Waymouth, J.L. Hedrick, Guanidine and amidine organocatalysts for ring-opening polymerization of cyclic esters, Macromolecules 39 (2006) 8574-8583.

[40] R.C. Pratt, B.G.G. Lohmeijer, D.A. Long, R.M. Waymouth, J.L. Hedrick, Triazabicyclodecene: a simple bifunctional organocatalyst for acyl transfer and ring-opening polymerization of cyclic esters, J. Am. Chem. Soc. 128 (2006) 4556-4557.

[41] R. Todd, S. Tempelaar, G. Lo Re, S. Spinella, S.A. McCallum, R.A. Gross, J.M. Raquez, P. Dubois, Poly( $\omega$-pentadecalactone)-b-poly(l-lactide) block copolymers via organic-catalyzed ring-opening polymerization and potential applications, ACS Macro Lett. 4 (2015) 408-411.

[42] M. Fevre, J. Vignolle, Y. Gnanou, D. Taton, Organocatalyzed ring-opening polymerizations, Polym. Sci.: Comprehen. Ref. 4 (6) (2012) 67-115.

[43] W. Li, K. Matyjaszewski, Star polymers via cross-linking amphiphilic macroinitiators by AGET ATRP in aqueous media, J. Am. Chem. Soc. 131 (2009) 10378-10379.

[44] T. Shibata, S. Kanaoka, S. Aoshima, Quantitative synthesis of star-shaped poly(vinyl ether)s with a narrow molecular weight distribution by living cationic polymerization, J. Am. Chem. Soc. 128 (2006) 7497-7504.

[45] T.K. Goh, S. Yamashita, K. Satoh, A. Blencowe, M. Kamigaito, G.G. Qiao, Highly efficient synthesis of low polydispersity core cross-linked star polymers by Ru-catalyzed living radical polymerization, Macromol. Rapid Commun. 32 (2011) 456-461.

[46] M. Jesberger, L. Barner, M.H. Stenzel, E. Malmström, T.P. Davis, C.J. BarnerKowollik, Hyperbranched polymers as scaffolds for multifunctional reversible addition-fragmentation chain-transfer agents: a route to polystyrene-core-polyesters and polystyrene-block-poly(butyl acrylate)-core-polyesters, J. Polym. Sci. Part A: Polym. Chem. 41 (2003) 3847-3861.

[47] H. Gao, K. Matyjaszewski, Synthesis of star polymers by a new "core-first" method: sequential polymerization of cross-linker and monomer, Macromolecules 41 (2008) 1118-1125.

[48] P. Timashev, D. Kuznetsova, A. Koroleva, N. Prodanets, A. Deiwick, Y. Piskun K. Bardakova, N. Dzhoyashvili, S. Kostjuk, E. Zagaynova, Y. Rochev, B. Chichkov, V. Bagratashvil, Novel biodegradable star-shaped polylactide scaffolds for bone regeneration fabricated by two-photon polymerization, Nanomedicine (Lond.) 11 (2016) 1041-1053.

[49] A. Michalski, M. Brzezinski, G. Lapienis, T. Biela, Star-shaped and branched polylactides: Synthesis, characterization, and properties, Prog. Polym. Sci. 89 (2019) 159-212.

[50] M.M. Thuo, W.F. Reus, C.A. Nijhuis, J.R. Jabulani, C. Kim, M.D. Schulz, G.M. Whitesides, Odd - even effects in charge transport across self-assembled monolayers, J. Am. Chem. Soc. 133 (2011) 2962-2975.

[51] M. Buda, The use of calculated reorganization energies in experimental electrochemical kinetics, J. Solid State Electrochem. 17 (2013) 3027-3037. 